WSRC-TR-94-0386

Rev 1

June 1996

\title{
Estimating Dispersion from a Tornado Vortex and Mesocyclone ${ }^{(U)}$
}

A. H. Weber and C. H. Hunter

Prepared for the U.S. Department of Energy under contract no. DE-AC09-89SR18035

DISTRIBUTION OF THS DOCUMENT IS UNLIMFED 



\section{Contents}

Executive Summary 1

Introduction 3

Tornado Development 5

Tornado Details 7

Tornado Debris Patterns 9

Previous Dispersion Modeling of

Radioactive Pollutants in a Tornado 11

Previous Tornado Dispersion Calculations using the Puff-Plume Model 13

Recommended Model for Tornado Dispersion 15

Results from the Recommended Model 17

Conclusions 19

References 21

Appendix A 33 


\section{List of Figures}

Figure 1.

Figure 2.

Planimetric view of a tornadic thunderstorm at the surface. The thick line encompasses the radar echo.The thunderstorm wave-like "gust-front" structure is shown with a solid line and frontal symbols. Surface positions of the updraft are finely stippled; the forward-flank downdraft (FFD) and the rear-flank downdraft are coarsely stippled along with associated streamlines. Likely tornado locations are shown by encircled Ts. The major cyclonic tornado is most probable at the wave apex, while a minor cyclonic tornado may occur at the bulge in the cold front (southern T), which also marks the favored location for new mesocyclone. Anticyclonic tornadoes, in any, are found even farther south along the cold front (from Davies-Jones [1986] who adapted the figure from Lemon and Doswell [1979]). 23

\section{Figure 3.}

Figure 4.

Figure 5.

Figure 6a.

\section{Different flow regions for a tornado (Davies-Jones 1986) 24}

Effect of increasing swirl ratio on vortex flow: (a) weak swirl-flow in boundary layer separates and passes around comer region; (b) one-cell vortex; (c) vortex breakdown; (d) two-cell vortex with downdraft impinging on the ground (core radius increases rapidly with increasing swirl ratio); (e) multiple vortices. The connected CL indicates the centerline (from Davies-Jones 1986). 25

Maximum ground-level centerline air concentration $\left(\mathrm{m}^{-3}\right)$ vs. downwind distance $(\mathrm{km})$ from initialization point in storm from Pepper's second moments mode (Pepper 1981) 26

Maximum ground-level centerline air concentration $\left(\mathrm{m}^{-3}\right)$ vs. downwind distance $(\mathbf{k m})$ from Pepper's Gaussian model (Pepper 1981) 27

Maximum time-integrated ground-level centerline air concentration $\left(\mathrm{sec} \mathrm{m}^{-3}\right)$ vs. downwind distance $(\mathrm{km})$ for different mean translation speeds $7.5-22.5 \mathrm{~m} / \mathrm{sec}$. The downdraft speed is $10 \mathrm{~m} / \mathrm{sec}$ and the height of the cylindrical mesocyclone is $3500 \mathrm{~m}$. The Haynes and Taylor results are identified in the legend as'75 M DP'. 28

Figure 6b.

As in Figure 6a except for different downdraft speeds, $10-20 \mathrm{~m} / \mathrm{sec}$. The translation speed is $7.5 \mathrm{~m} /$ $\mathrm{sec}$ and the height of the cylindrical mesocyclone is $3500 \mathrm{~m} .29$

Figure 6c.

As in Figure $6 \mathrm{~b}$ for different initial heights of the center of the mesocyclone cylindrical volume source. The translation speed is $7.5 \mathrm{~m} / \mathrm{sec}$ and the downdraft speed is $10 \mathrm{~m} / \mathrm{sec}$. 30

Figure 7. Maximum ground-level centerline air concentration $\left(\mathrm{m}^{-3}\right)$ vs. downwind distance $(\mathrm{km})$ from the recommended model with the translation speed $=7.5 \mathrm{~m} / \mathrm{sec}$, downdraft speed $=10 \mathrm{~m} / \mathrm{sec}$, and the release height $=3500 \mathrm{~m}(\mathrm{H} 3500 \mathrm{CYL})$; and from Pepper's (1981) second moments model with translation speed $=13.4 \mathrm{~m} / \mathrm{sec}$ (13 PEPPE). 31 


\section{Executive Summary}

Atmospheric dispersion modeling is required to ensure that a postulated breach in radionuclide storage containers at the Savannah River Site (SRS) from a tomado strike of Fujita-scale intensity $F 2$ or higher will not result in an unacceptable dose to individuals. Fujita-scale tornado descriptions are included in Appendix A of this report.

Dispersion models previously used at SRS for estimating dispersion following a tornado strike were developed by D. W. Pepper in 1975 (DP-1387, Dispersion of Small Particles) and H. R. Haynes and D. W. Taylor in 1983 (DPST82-982, Estimating Doses from Tornado Winds). Research conducted in 1983 on the formation and evolution of tornadic thunderstorms has lead to a more complete understanding of the tornado vortex and associated persistent updraft and downdraft regions within the parent thunderstorm.

To ensure that appropriate, contemporary methods are used for safety analysis, the Pepper model and the Haynes and Taylor model were evaluated with respect to current knowledge of circulations within tornadic thunderstorms. Pepper's model is complex numerically but contains most of the desired physical parameterizations. Haynes and Taylor's model is used with the Puff-Plume model (an emergency response model on the Weather INformation and Display System at SRS) and has provisions for radionuclide deposition and rainout. Haynes and Taylor assumed heavy rain following the tornado for a period of ten minutes, followed by a lighter rain for another ten minutes, then no rain for the period when the material is transported to $100 \mathrm{~km}$ downwind. However, neither model incorporates the effects of a nearby thunderstorm downdraft.
A revised model, which employs a simple Gaussian dispersion algorithm and provisions for a single persistent downdraft, is proposed for use at SRS. The model presumes respirable particles are immediately releases and assimilated in the tornado vortex. Thereafter, the particles are lifted to the base of a counter-clockwise rotating column of air known as a "mesocyclone". The mesocyclone is located adjacent to a substantial persistent downdraft, which can eventually carry the elevated particles back toward the surface

Results from this proposed model were compared with the results of the Pepper model and the Haynes-Taylor approach. The recommended model is found to yield lower values for the time-integrated concentration (normalized by source strength) over short distance ranges but higher values for longer distances, compared to the Haynes-Taylor approach. Both the recommended model and the Haynes-Taylor approach give results, which exceed those of Pepper's model. The recommended model was expressly composed with conservative, yet reasonable assumptions regarding the major factors influencing dispersion after a tornado strike. Results are provided for ranges of wind speed, downdrafts, and initial release heights of the mesocyclone.

The scenario considered in this report does not include an extended release after a tornado strike. Winds associated with tornadoes categorized as F2 and above are assumed to result in complete destruction of barriers to the environment and would likely cause a sudden release of materials into the tormado vortex. Another possibility is bleeding or slow discharge of the radionuclides after the tornado vortex moves over the damaged facility. This possibility would require a more conventional approach because the dispersion would be primarily horizontal without the effect of significant updrafts or downdrafts. 


\section{Introduction}

Tornadoes are among the most violent atmospheric storms and consequently pose a challenging problem for risk analysis and safety studies. The U. S. Department of Energy design standard for natural phenomena (DOE 1994) recommends that an SRS facility that has a performance goal of Performance Category 3 should be evaluated for sustained winds of 61 meters per second $(\mathrm{m} / \mathrm{s})$ (137 miles per hour) and for peak winds of 69 meters per second $(\mathrm{m} / \mathrm{s})$ (155 miles per hour). Winds of this magnitude are highly unlikely to be found anywhere except within the vortex (including the walls) of the tornado itself. Therefore, wind damage can be limited to a direct strike by the tornado (i.e., the tornado funnel is in contact with the surface and moves in a path such that its circular envelope sweeps across the facility in question). A glancing strike or a situation where the tornado funnel temporarily loses contact with the ground would not expose the facility to the full strength of the wind. Releases resulting from tomado-generated missiles are assessed by conventional modeling techniques. Modeling of collateral releases were not addressed in this report.

Previous dispersion models at SRS were derived by D. W. Pepper in 1981 and H. R. Haynes and D. W. Taylor in 1983. Pepper's model accounts for uptake of radionuclides by the tornado vortex and mixing material throughout the parent thunderstorm, followed by conventional dispersion from advection, turbulent diffusion, and wet deposition. Calculations of ground-level concentration were based on a numerical solution to the advection-diffusion equation. Haynes and Taylor's model is based on a Gaussian dispersion model (the Puff-Plume model on the WIND System) and has provisions for radionuclide deposition and rainout. Haynes and Taylor assumed heavy rain following the tornado for ten minutes, followed by lighter rain for another ten minutes, then no rain when the material is transported to $100 \mathrm{~km}$ downwind.

Research that has been conducted since these earlier models were formulated has demonstrated the importance of thunderstorm downdrafts in mesoscale circulations accompanying tornadoes. The objective of this study is to determine revised estimates of ground-level concentration following a radioactive release from a F2/F3 tornado strike using a simple Gaussian model in which the downdraft is allowed to bring material to the ground. The methodology assumes a direct tornado strike and immediate, complete entrainment of the radionuclides into the core of the tornado. It is possible for a strong F2 tornado to damage a facility or container and result in a slow leak of radionuclides to the atmosphere. These situations would require an accident analysis that considers a ground release of the radionuclides. This scenario is not considered in this report.

Tornado structure may take on one of three basic forms:

1. single spiraling updraft vortex

2. single spiraling updraft with core downdraft

3. multiple "planetary" vortices (suction spots) within a main vortex.

Since there are three possible vortex forms for the tornado strike, a spectrum of damage scenarios are possible. Regardless which of the three vortex forms is present when the tornado strikes the facility, for the purpose of constructing dispersion curves, we assume that the same tornado vortex that damages the facility (releasing the radionuclides) immediately draws the particles into the vortex and transports them spiraling upward within the vortex.

The interaction of the released radionuclide aerosols with precipitation might be of crucial importance in some accident scenarios. The aerosols might become scavenged by raindrops within the parent thunderstorm, which then either evaporate before reaching the surface or are deposited on the ground with rain. If the material reaches the ground as wet deposition then the particles would be temporarily restricted from reaching the lungs in large percentages through respiration. Resuspension would need to be considered as a separate process (acting on time scales measured in hours or days after the passage of the tornado vortex).

If a sudden release and immediate lifting of the particles does not occur, then other outcomes would have to be considered, depending on the nature of the accident being analyzed. For example, aerosols from a liquid pool might be blown horizontally along the surface by strong winds in the aftermath of the tomado strike. This latter case could be handled with standard Gaussian models using an appropriate wind speed. 


\section{Tornado Development}

Ordinary convective clouds grow rapidly and a small percentage may develop into thunderstorms that decay over a 40 to 60 minutes. A non-tornadic thunderstorm often produces heavy rain, large hail, and damaging winds; only the tornadic thunderstorms produce a rotating vortex and accompanying violent winds that flatten substantial natural and man-made structures.

Tornadic thunderstorm development in the Midwest and other areas has been observed over the past several years, and now better ideas are beginning to emerge about their formation and structure. However, as with almost any weather-related phenomena, there are exceptions to prevailing views and observations that are difficult to reconcile with existing models. Consequently, tornado and thunderstorm research continues at a relatively high rate of funding and national interest. Substantial progress in modeling of tornadic storms has occurred by taking advantage of computer hardware and software advances, c.f., Wicker (1990).

Tornadic thunderstorms in the Midwest and Great Plains often have features such as an overshooting top (dome), shelf cloud, tail cloud, and wall cloud that are absent in non-tornadic thunderstorms. These features are not always easily observed in many of the Southeast's tornadic thunderstorms. This is due partly to limited horizontal visibility caused by trees and terrain features in contrast to the flat prairies of the Midwest. Bluestein and Golden (1993) noted that tornadoes in the Southeast often occur late at night and are frequently ensheathed by heavy rain curtains that severely limit identification of tornadic thunderstorm features.

Between 1960 and 1980, a number of important observations, aided by weather radars, enabled atmospheric scientists to better understand the evolution of the so-called tornadic supercell. An organizing stage consists of an alternating group of growing and decaying thunderstorm cells progressively moving downwind. At some point, a single cell grows horizontally and vertically to an extent that it dominates all others and begins to propagate to the right of the environmental winds at all levels. This cell is called a "supercell", and it develops when there is substantial vertical shear of the environmental wind (e.g., the lowlevel wind is from the south, the mid-level wind is from the southwest, and the upper-level wind is from the west).
Davies-Jones (1986) noted that tornadic thunderstorms are characterized by the formation of a mesocyclone, an organized counterclockwise (as viewed from above in the Northern Hemisphere) horizontal circulation of air about a vertical axis that has a horizontal extent of $5-10 \mathrm{~km}$ initially, dominating at the middle level $(3-7 \mathrm{~km}$ above ground) of the storm. Later in the storm's development, the mesocyclone's base can be identified visually by a cylindrical, rotating cloud (or discrete lowering of the cloud base $1-10 \mathrm{~km}$ in diameter). This lowering of the cloud base is called a "wall" cloud. The wall cloud aids a "severe storm spotter's" identification of tomado potential. This cloud may have spiral striations on its base or sides. Very intense upward motions are observed on the forward sides of wall clouds. The tornado is almost always suspended from a wall cloud until near the end of its life.

Often, gradual cloud evaporation is observed in the wall cloud and main thunderstorm tower base on the rear and right sides of the tornado, forming a clear slot. This observation is consistent with a developing, unsaturated, rearflank downdraft and reveals that tomadoes form in strong vertical velocity gradients near the edge of the parent updraft and close to a downdraft.

According to Davies-Jones (1986), tomadoes can be categorized into two main groups, depending on the absence or existence of a mid-level mesoscale parent circulation (3-9 $\mathrm{km}$ in diameter). Type A tornadoes form on the gust front under the flanking line of new cells that continuously develop on the right rear flank of severe thunderstorms (Figure 1). These tornadoes can be a considerable distance (up to $20 \mathrm{~km}$ ) from the rain shaft of the parent storm. Eddies up to $1 \mathrm{~km}$ in diameter are sometimes seen at cloud base in association with these tornadoes but are too small and weak to be identified by radar.

Tornadoes of Type B form from a cyclonically rotating mesovortex (mesocyclone) that is linked spatially with the main updraft. Occasionally Type A tornadoes may evolve into Type B. Severe tornadoes belong to Type B. A pendant or hook forming on the right rear of an echo often identifies mesocyclones on radar. The hook is caused by precipitation drawn into a cyclonic spiral by the winds, and the associated notch in the echo is caused by precipitation-free, warm moist air flowing into the storm. The inflow is confined primarily to the lowest $3 \mathrm{~km}$. These winds and temperature fields at low levels in a mesocyclone resemble the classic model of a middle-latitude 
cyclone. Significant cyclonic wind shifts are observed at the "pseudo-cold" and "pseudo-warm" fronts (the latter is the part of the gust front that is ahead of the wave apex in Figure 1). Tornadoes may form either at the apex of the wave or toward the edge of the mesocyclone where the pseudo-cold front is a favored location. Mesocyclones occasionally persist for a few hours and may spawn several tomadoes. The tornadoes are steered by the larger mesoscale circulation in which they are embedded.

Browning's (1964) model of the tornadic thunderstorm is based on a circulation in which warm, moist low-level air is ingested into a single large updraft that is supported by buoyancy from the latent heat of condensing water vapor. Evaporative cooling within the region of heaviest precipitation north of the updraft drives the main downdraft. As cooler and drier air spreads out beneath the storm, it collides with the warm, moist inflow along a line called the gust front.

An important feature of this storm model is that the updraft and downdraft are physically separated and that these air currents enhance rather than attenuate or destroy one another. (In an environment with weak shear the updraft is attenuated or destroyed by the downdraft.)

In the second, or mature stage, of the tornadic thunderstorm, the mesocyclone intensifies down to lower levels, and the downdraft intensifies at middle and low levels. The updraft also intensifies and a hook-shaped radar echo will sometimes be visible on the radar. Funnel clouds and weak tornadoes usually form at this time. At the surface, there is a region of cold air produced by the evaporation of precipitation that spreads out and forms a "gust front". The gust front is the interface between the spreading cold air and the warm, moist inflow air.

In the third, or final stage, of the tornadic thunderstorm, the gust front surges strongly and becomes highly contorted in the vicinity of the main updraft. The rear-flank downdraft is inferred from the "clear slot," an area through which the sun may shine that is produced by rapid erosion of cloud material just southwest of the tornado. The tornado is located between the updraft and the rear-flank downdraft. The tornado will maintain full strength for several minutes before the vortex loses contact with the ground and becomes invisible.

Although the tornado is located close to the storm's downdraft, close inspection of film recordings shows that on and just outside the funnel there is very intense rising motion. From detailed observations and analyses of the motion of dust, debris and cloud tags, deductions of the wind field may be made (see the review by Golden 1976). Although there is some question about the more detailed conclusions drawn from these analyses, there are common basic features. First, the most intense winds occur very close (within $100 \mathrm{~m}$ ) to the ground. Second, the vertical velocity (upward) is comparable in magnitude with the horizontal velocity, and it too reaches very strong values close to the ground. 


\section{Tornado Details}

Davies-Jones (1986) states that the core of a tomado is two orders of magnitude smaller in horizontal dimension than the parent thunderstorm and the total energy and circulation of the parent storm greatly exceed those of the tornado. Most tornadoes are relatively weak and short-lived (1-2 $\mathrm{min}$ ), and they typically inflict damage to an area 2 $\mathrm{km}$ long and $50 \mathrm{~m}$ wide while moving from the $\mathrm{SW}$ at 15 $\mathrm{m} / \mathrm{sec}$ (Fujita and Pearson 1973). In extreme cases, the path length may exceed $150 \mathrm{~km}$, the width of the damage may be $3 \mathrm{~km}$, the lifetime may exceed $1 \mathrm{hr}$, and the translation speed may reach $30 \mathrm{~m} / \mathrm{sec}$. Sixty percent of tornadoes move from the SW, and only $4 \%$ have a westward component of motion (Wolford 1960). Wakimoto (1983) estimates that 1 of 700 tornadoes has anticyclonic circulation.

A reasonable picture of the tornado's structure is beginning to emerge. Davies-Jones (1986) presented a summary of vortex flow features pertinent to tomado structure:

The vortex flow consists of several different regions which interact strongly (see Figure 2). Region 1a comprises the outer flow away from the ground and the axis of rotation. It consists of converging air that approximately conserves its angular momentum. As a result it spins faster as it approaches the axis. However, maximum tangential velocities are limited by two factors: (1) the potential energy available for driving the flow is finite, and (2) close to the axis viscous and eddy torques considerably reduce the parcel's angular momentum. The tangential velocity must be zero on the axis; otherwise centrifugal forces would be infinite. Region $1 \mathrm{~b}$, the core, is the region surrounding the axis and extending outward roughly to the radius of maximum tangential winds. Owing to the importance of diffusion, the core is approximately in solid-body rotation, a flow that is, in the absence of axial flow, stable against radial displacements of fluid and supports waves which are frequently seen moving up or down tornado funnels. There is almost no entrainment into the core. The flow along the axis can be either upward of downward according to theory, and there may be stagnation points above the ground separating axial upflow and downflow. The hollow appearance of many waterspouts, and the appearance of the spray and dust clouds around some waterspouts and tomadoes, and in laboratory models suggest that axial downdrafts often reach the surface. Morton (1966) has shown that in and near the core tangential and vertical velocities are of the same order, and radial velocities are an order of magnitude smaller.

Vortex interaction with the ground creates a turbulent boundary layer (region II), perhaps a few hundred meters deep, of reduced tangential velocities. Thus the cyclostrophic balance between outward centrifugal and inward pressure gradient forces that exists in region 1 is upset, and the net inward force derives a strong inflow along the surface into the corner region III, where, by continuity, a strong updraft into the comer must exist. The low-level inflow into a tornado core occurs primarily through the lower part of the boundary layer and the corner region.

Vortices are destroyed by inflow from their ends. Vortex interaction with the lower surface places restrictions on the low-level inflow. Aloft the vortex must terminate in a buoyant updraft (region IV), so that downflow into the core is also restricted. Large horizontal shears measured by Doppler radar suggest that the tornado sometimes reach great vertical extents ( $>10 \mathrm{~km}$ ), although, presumably, the core spreads and tangential velocities decrease with height. However, in other cases the tornado signature disappears above $3 \mathrm{~km}$. Overall the tornado generally tilts to the left of the storm-motion vector with height. The overall tilt is typically $25^{\circ}$ from the vertical.

Since tornadoes must terminate somewhere aloft, they must spread laterally with height. Because of this spreading, the swirl and meridional (radial-axial) components of motion are coupled though the pressure field.

By varying the swirl ratio (the ratio of the tangential velocity to the vertical velocity), the behavior of vortex flow changes as shown in Figure 3 (from Davies-Jones 1986) from a one-cell vortex - to vortex breakdown-to two-cell vortex with downdraft impinging on the ground-to multiple vortices. 


\section{Tornado Debris Patterns}

Information about the spread of tornado debris, which is usually thought of as moderately heavy objects (0.25-16.0 oz) with fall velocities in the range 0.01 to $5 \mathrm{~m} / \mathrm{sec}$, is of great interest and has been gathered and analyzed by atmospheric scientists (Anderson 1985; Peterson 1993). The main problem is that these data are infrequently available, and there is usually a lapse of several years between tornado occurrences whose debris patterns are suitable for analysis.

The recent study by Anderson relied on interviews with more than 200 people in the vicinity of Barneveld, Wisconsin, to map out the tomado debris pattern. Barneveld was the site where a severe (F-5) tornado struck in June 1984. The funnel sucked up many tons of material from the village of Barneveld and deposited the debris along a trail to the northeast up to $220 \mathrm{~km}(137 \mathrm{mi})$ away. The debris fall-out pattern had the following features:

- A more or less continuous area of debris to the left of the tornado path stretched from Bameveld to west of Neenah, some $170 \mathrm{~km}$ (102 mi) northeast. The debris pattern had a width of a few hundred yards just north of Barneveld and then widened to a maximum of $32 \mathrm{~km}$ $(20 \mathrm{mi})$ at a downwind distance of $104 \mathrm{~km}(65 \mathrm{mi})$ downstream. Within this contiguous debris area, the heavy material was deposited along a narrow path from Barneveld to east of Redgranite, a stretch of about 136 $\mathrm{km}(85 \mathrm{mi})$. The path of the heavy material showed branching at three places along its length, and it was partially interrupted in the Portage region. The lighter materials were not deposited symmetrically around the heavy debris path but lay more to the east, making the heavy debris path lay nearer the western edge of the contiguous deposit area.

- Paper debris was found throughout the contiguous area with a wider extent than the light debris. Paper debris was found in widely scattered locations north of the contiguous area and reached some $32 \mathrm{~km}(20 \mathrm{mi})$ northwest. The maximum width of this scattered paper was $37 \mathrm{~km}(23 \mathrm{mi})$ at $176 \mathrm{~km}(110 \mathrm{mi})$ downstream of Bameveld.

- The light material was confined to the contiguous area with one exception. A pouch lettered "Barneveld State Bank" was found in Mayville, $138 \mathrm{~km}(86 \mathrm{mi}) \mathrm{ENE}$ of Barneveld.
- The eastern edge of the contiguous area displayed indentations and outward bulges for both light and paper material. In some of these cases, the indentations and bulges roughly correlated with branching of the heavy material.

Anderson (1985) concluded that the heavy debris contours in the fallout pattern for the Barneveld tornado did not result from environmental winds acting on a vertical column at Barneveld. All debris heavier than $2 \mathrm{~m} / \mathrm{sec}$ fall speed was transported by environmental winds to the right of the observed fallout pattern regardless of its height of origination up to $12 \mathrm{~km}$. Some of the light debris and paper found on the eastern side of the fallout could have originated from a vertical plume over Barneveld provided its fall speed was less than $2 \mathrm{~m} / \mathrm{sec}$. The complicated distribution of material was probably from a combination of mesocyclone circulation and environmental winds acting on the original cloud of debris sucked up by the tornado funnel at Barneveld.

As early as 1917 , Wegener observed that the tornado developed to the right of the tallest part of the thunderstorm (as viewed from behind). It was assumed that debris was carried upwards by the tornado. The deposition of debris to the left side of the tornado path resulted in the concept that the tornado tube was bent horizontally (and then descended to near the ground) toward the left side of the storm. For these early cases, next to nothing is available relating to the environmental winds.

Peterson (1993) provided additional case studies to show that the debris pattern is normally to the left of the tornado path. He noted, "These events and others not cited from the last hundred years share similarity in characteristics: far-field debris deposited primarily to the left of the hail swath, which in turn is to the left of the tornado track: distances in the tens of kilometers from the points of origin."

The flow of air in tornadic thunderstorms has been deduced from Doppler radar observations and simulated numerically. Klemp (1987) presented a schematic synthesis of these studies. The schematic streamflow hints that objects could be deposited to the left of the storm track as long as they do not ascend above the mid-levels. Higher lofting of items could result in them being carried to the right of the track. In general, this appears consistent with far-field debris observations. 


\section{Previous Dispersion Modeling of Radioactive Pollutants in a Tornado}

Pepper (1981) addressed modeling radioactive pollutants in a tornadic storm at SRS. He assumed a unit source of radioactive pollutant per cubic meter was picked up by the tornado and lifted into the thunderstorm cell. The radioactive pollutant was assumed to consist of particles with diameters less than 10 microns so that they essentially followed air motion. Once the pollutant reached the thunderstorm cell (defined to be a point where vertical velocity of the tornado vortex was less than the updraft velocity of the thunderstorm), the puff was assumed to be dispersed by dynamics of the thunderstorm cell. According to Fujita (who was consulting with Pepper during the development of the code), the radioactive puff becomes dispersed throughout the thunderstorm cell within about 20 minutes.

Pepper assumed the concentration pattern to be limited to the size of the thunderstorm cloud with a maximum peak at each level near the position of the tornado axis. The initial concentration within the thunderstorm cell was set by using a skewed log-normal distribution with the maximum values centered on the axis of the tornado. Once the initial distributions were established, advection, turbulent diffusion, and rainout scavenging acted to disperse the pollutant cloud.

F. Pasquill, dispersion meteorologist, and E. Kessler, Director, National Severe Storms Laboratory, concurred with Pepper on his assumption that the pollutants become well mixed throughout the thunderstorm cell. Pepper (1981) stated, "It is the large scale flow field of the thunderstorm which ultimately determines the dispersion pattern of the pollutant, not the uptake and radial inflow of the shorter lived tornado."

Assumptions about the vertical wind distribution, eddy diffusivities, etc., are contained in Pepper's report. Using the method of second moments, a quasi-Lagrangian finite difference technique (Egan and Mahoney 1972), Pepper solved the advection-diffusion equations numerically. Output from his model consists of concentration values specified within individual cell volumes. Pepper presented results for a unit release as isopleths of ground-level concentration. Maximum ground-level centerline values of air concentration $\mathrm{X} / \mathrm{Q}\left(\mathrm{m}^{-3}\right)$ were shown for different storm translation speeds as a function of downwind distance (Figure 4). Pepper's model also showed that early deposition of radionuclides occurs within 10-20 minutes after the initial dispersion of concentration within the storm cell.

To compare his numerical results with another model, Pepper chose a modified Gaussian puff model and calculated ground-level concentration X/Q $\left(\mathrm{m}^{-3}\right)$. Pepper's Gaussian model results are shown in Figure 5, but one should be aware that he assumed an initial $\sigma_{\mathrm{z}}=12,000 \mathrm{~m}$, $\sigma_{\mathrm{y}}=5000 \mathrm{~m}$, and release height of $6500 \mathrm{~m}$. Pepper stated that these large initial values of the dispersion coefficients were chosen to represent the material being dispersed within the parent thunderstorm cloud. It is possible that such material could be brought to the surface more quickly than indicated by Pepper's Gaussian model, particularly by downdrafts operating within the parent thunderstorm cloud; hence, his Gaussian model results would be nonconservative by neglecting this mechanism.

Pepper's maximum concentrations differ by more than three orders of magnitude between the two models. Pepper ascribes this difference between the two models to the initial height at which the Gaussian model begins to diffuse the concentration, and to the high energy dissipation rate used to generate the diffusion parameters he used. Pepper mentioned a model by Kao (1976) (which included the effects of scavenging and topography) generated concentration values comparable to Pepper's Gaussian model.

Pepper commented that while the versions of his model used to generate the dispersion curves in Figures 4 and 5 did not contain the effects of updrafts and downdrafts, his experimentation with this parameter's effect had produced increased dilution in the vertical plane initially, followed by rapid increases of concentration at the ground. 


\section{Previous Tornado Dispersion Calculations using the Puff-Plume Model}

Haynes and Taylor (1983) provided curves of "time integrated ground-level concentration $\left(\mathrm{sec} / \mathrm{m}^{3}\right)$ " from respirable particles carried aloft in a puff after a tomado impact on a hypothetical SRS facility. The methodology used by Haynes and Taylor relied heavily on similar assumptions regarding tornado "uptake" of the respirable particles used by Pepper $(1981,1975)$. However, Haynes and Taylor utilized the Puff-Plume model (Garrett and Murphy 1981) as the "model of choice" for the calculations to develop their curves of time-integrated concentration.

Haynes and Taylor composed a three-stage dispersion process. The first stage consisted of a puff in neutral atmospheric conditions and heavy rains for $10 \mathrm{~min}$, followed by more neutral conditions and light rain for $20 \mathrm{~min}$, and lastly, unstable conditions with no rain (long enough for the puff to be transported to $100 \mathrm{~km}$ downwind from the source). Since these are really discontinuous processes, Haynes and Taylor were forced to re-initialize the PuffPlume model with the puff size at the end of each preceding stage. Since the Puff-Plume model version used in 1981 only printed the value of $\sigma_{y}$, the value of $\sigma_{z}$ had to be calculated separately. Haynes and Taylor calculated $\sigma_{z}$ using plume formulas, not those for a puff; however, this is unlikely, in view of the other assumptions for their tornado model, to be a significant problem.

A point that remains puzzling in the Haynes and Taylor documentation is that the "time integrated curves" provided in their figures have units of $\mathrm{sec} / \mathrm{m}^{3}$ but are denoted by X/Q. Puff concentration/source strength values are usually denoted by the symbols X/Q and would have units of $\mathrm{m}^{-3}$ (as was true in Pepper's 1981 model above). Integrated exposure values (i.e., relative concentration integrated with respect to time are often denoted with the symbols $\Psi / Q$ ( $\mathrm{sec} / \mathrm{m}^{-3}$ ) (Slade 1968). Since the output from Puff-Plume for a puff release is expressed as instantaneous concentration rather than integrated concentration, values of $\Psi / Q$ must be derived from $X / Q\left(\mathrm{~m}^{-3}\right)$ as a function of time. For a Gaussian puff distribution, a multiplicative factor of $2^{1} / \pi^{2} /^{2} \sigma_{x} / \mathrm{u}$ would have to have been applied to $X / Q$ to obtain $\Psi / Q$. (In puff dispersion, it is common to assume $\sigma_{\mathrm{x}}$ approximately equal to $\sigma_{\mathrm{y}}$ ) No mention of this factor is made in the Haynes and Taylor report.

It is possible that Haynes and Taylor may have selected the plume option (instead of the puff) of the PUFF-PLUME code. By doing that, the equations for the concentration $\mathrm{X} /$ $\mathrm{Q}\left(\mathrm{m}^{-3}\right)$ have the same terms for the time-integrated "exposure" $\Psi / Q\left(\mathrm{sec} / \mathrm{m}^{-3}\right.$ ) as for the puff. As was mentioned earlier, this method contains an inconsistency since plume rather than puff dispersion coefficients are being used.

It is not worthwhile to labor over exactly what method Haynes and Taylor followed since the objective here is to obtain a better estimate of tornado induced dispersion. But it is important to remember in comparing Pepper's (1981) model results with Haynes and Taylor (1983) that there is a significant difference in meaning for the symbols that identify the plot axes.

A significant advantage provided by the Haynes-Taylor calculations is that the deposition and rainout processes are well modeled since those are the primary strengths of Garrett and Murphy's Puff-Plume model. Pepper's model also contains provisions for these processes. 


\section{Recommended Model for Tornado Dispersion}

While Pepper's model may have provided a good basis to build an improved tornado model, the 3500-line FORTRAN code contained in an appendix of his 1981 report contains no documentation of any kind or instructions on how to run the model. A project to implement Pepper's model would have taken several weeks longer than was allotted for this project, so it was decided to use a simple Gaussian model with more conservative estimates of the initial puff dimensions (than Pepper used with his Gaussian approach) and to make allowance for downdrafts to bring the material to the surface.

Our recommended model is based on what we now understand as a reasonable consensus of tornado structure. This is based on more information than was available to the authors of the previous two models, particularly with regarding the relative position that the tornado vortex has $t$ to the updrafts and downdrafts. Our understanding (Figure 1) is that the tornado vortex occupies a position between the main tomado updraft and downdraft regions, and that the updraft precedes both the vortex and the downdraft in a "classical" tornado strike. In addition, we now understand that the vortex structure itself may have one of four major forms (Davies-Jones 1986), reproduced as Figure 3a-e in all of which the major motion is strongly upward.

One particularly important parameter influencing dispersion is the size of the mesocyclone to which the tornado vortex is attached. It is only possible to set some reasonable limits in the absence of extensive Doppler radar data. The mesocyclone's upper bound is the total width of the parent thunderstorm (perhaps 15-30 km). Earlier in this report we noted that Bluestein and Golden (1993) had estimated the size range of the mesocyclone between $5-10 \mathrm{~km}$ and that Davies-Jones (1986) gave the range as $1-10 \mathrm{~km}$. The tomado funnel size establishes the limiting minimum diameter for the mesocyclone. An F2 or greater tornado is not likely to have a width less than $100 \mathrm{~m}$. Another estimate of the horizontal width of the mesocyclone is the close-in debris pattern, which for the Barneveld tornado was a few hundred meters. Based on these data, a reasonable lower bound value of $1000 \mathrm{~m}$ was selected as the diameter of the mesocyclone to be modeled.

Published data on the vertical extent of the mesocyclone is even less conclusive. A vertical depth that is equal to the mesocyclone's horizontal diameter is believed to be a reasonable estimate.
Using these constraints on the initial size of the release of radioactive particles following an F2 or F3 tornado strike, the following describes a simple Gaussian model for dispersion:

- The model assumes a tornado strikes an SRS facility and releases one curie of respirable radioactive particulates similar to those assumed in the Pepper or the Haynes-Taylor model. The tornado moves with a translational speed in the range $7.5-22.5 \mathrm{~m} / \mathrm{sec}$. (This is also consistent with Pepper's [1981] and Haynes' and Taylor's [1983] models.)

- The radionuclides released from the structure are swept into a 100 -meter diameter vertical tornado vortex stretching to $3000 \mathrm{~m}$ high. Kessler (1992) reports that tornadoes have been observed to extend from $3 \mathrm{~km}$ to $10 \mathrm{~km}$ high. The lower height was chosen to produce conservative estimates of ground-level concentration. (Pepper chose a value of $6500 \mathrm{~m}$.) No mixing is assumed while the aerosols ascend to the top of the tornado vortex. The main tornado vortex tube or one of the suction vortices is assumed to carry the aerosols aloft to the elevated cylindrical mesocyclone $1000 \mathrm{~m}$ in diameter, whose base height is $3000 \mathrm{~m}$, and whose top is $4000 \mathrm{~m}$. During the ascent in the tornado vortex, the radionuclide cloud is acted on by a vertical component (upward) of velocity in the range $20-30 \mathrm{~m} / \mathrm{sec}$ (Wicker and Wilhelmison 1993). The time to make the ascent of $3000 \mathrm{~m}$ is 100 seconds during which time the tornado moves $750-2250 \mathrm{~m}$ horizontally.

- The mesocyclone completely mixes the radionuclides throughout its cylindrical volume while moving with the mean translational speed of the tornado (7.5-22.5 $\mathrm{m} / \mathrm{sec}$ ).

- The volume source represented by the mesocyclone is then acted upon by a downdraft with vertical velocity in the range $5-20 \mathrm{~m} / \mathrm{sec}$. The action of the downdraft is to bring the centerline of the diffusing cylindrical volume progressively towards the surface while the material is being transported downwind.

- As the mesocyclone's centerline reaches the surface one can assume either (1) the downdraft ceases its descent or (2) the downdraft continues to affect the remaining portion of the air mass, spreading it out in pancake fashion. Option 2 would amount to an enhancement for the horizontal dispersion coefficient. Therefore, option 1 was chosen to produce conservative results. 
- Converting the cylindrically shaped volume source to a Gaussian distribution is accomplished by a conventional method (Pasquill and Smith 1983). To make this conversion, $4.3 \sigma_{\mathrm{z}}$ is equated to the vertical height of the mesocyclone and $4.3 \sigma_{y}$ is equated to the horizontal diameter of the cylinder. For the mesocyclone adapted here, $4.3 \sigma_{\mathrm{z}}=4.3 \sigma_{\mathrm{y}}=1000 \mathrm{~m}$, so $\sigma_{\mathrm{y}}$ and $\sigma_{\mathrm{z}}=232 \mathrm{~m}$.

- Rainout could also bring the cloud material to the surface quickly; however, the particles being scavenged by raindrops are not available for breathing. Deposited alpha emitters on the ground cannot deliver dose except by resuspension and subsequent breathing in the lungs, a process that would require drying before becoming a factor, or by entering the food or drinking water. Because of the time lag between deposition and resuspension is highly variable and because the resuspension process itself is not completely understood, neither Pepper's nor models such as Puff-Plume take resuspension or ingestion into account.

For the dispersion model described above, only the choice of downdraft velocity would distinguish tornadoes in the $F 2$ and F3 intensity categories. In general, an F2 tomado would likely have lower downdraft velocities (in the 5-10 $\mathrm{m} / \mathrm{s}$ range) than an $\mathrm{F} 3$ tornado $(10-20 \mathrm{~m} / \mathrm{s})$. 


\section{Results from the Recommended Model}

The recommended model was used (following the steps shown in Calculation Q-CLC-G-00006) to compute several dispersion curves by varying the translational speed in the range $7.5-22.5 \mathrm{~m} / \mathrm{sec}$, the downdraft speed in the range $5.0-20.0 \mathrm{~m} / \mathrm{sec}$, and the initial release height in the range $3000-4000 \mathrm{~m}$. Results from the recommended model are shown in Figures 6a-c as curves of time-integrated concentration $\Psi / Q\left(\mathrm{sec} / \mathrm{m}^{-3}\right)$ (i.e., relative exposure). These values can be compared directly to Haynes' and Taylor's (1981) curves, one of which is shown in Figure 6a for the 75-m release height.

Results in Figure 6a for different translational speeds (release height $3500 \mathrm{~m}$ and downdraft velocity of $10 \mathrm{~m} /$ $\mathrm{sec})$ show that the revised estimates of $\Psi / Q\left(\mathrm{sec} / \mathrm{m}^{-3}\right)$ is very low in the $0.1-5 \mathrm{~km}$ range compared to the HaynesTaylor model. Since the Haynes and Taylor results are based on an effective release height of $75 \mathrm{~m}$ above ground, the contaminant reaches ground level much sooner (i.e., closer to the release point than for the recommended mode). Further downwind the curves become comparable and finally cross close to $10 \mathrm{~km}$ downwind after which the recommended model yields concentrations that are higher than those of Haynes-Taylor by a factor of 1-3. A major difference between the two models is that the recommended model allows for a downdraft, whereas the Haynes-Taylor approach does not. This is important since recent research has shown the mesocyclone spawning the tornado is adjacent to the major thunderstorm downdraft. Particles reaching the top of the mesocyclone are likely to be acted on by this downdraft. Once the downdraft brings the puff centerline to the surface, the only factors besides the wind speed that influence the calculations are the dispersion coefficients. The other major difference between the models is allowance for rainout and deposition of material by the Haynes-Taylor model. These processes remove material from the puff and deposit it on the ground where it is not able to be respired and deliver dose.
Results for the recommended model for different release heights (translational speed of $7.5 \mathrm{~m} / \mathrm{s}$ and downdraft velocity of $10 \mathrm{~m} / \mathrm{s}$ ) and for different downdraft speeds (release height of $3500 \mathrm{~m}$ and translation speed of $7.5 \mathrm{~m} / \mathrm{s}$ ) are shown in Figures $6 b$ and $6 c$, respectively. The curves given in these figures show that $\Psi / \mathrm{Q}\left(\mathrm{sec} / \mathrm{m}^{-3}\right)$ is low in the $0.1-2 \mathrm{~km}$ range compared to the Haynes-Taylor model. Further downwind the differences in the results from the two models are identical to those described for Figure 6a. Again, these differences are from the different ways in which the models account for downdrafts and deposition.

The results of Figure 6a-c cannot be compared directly to Pepper's results since his report does not show the variation of $X / Q$ with time. It is not possible to integrate $X / Q$ over time and produce curves for $\Psi / \mathrm{Q}$. We can, however, compare the concentration $X / Q$ directly, and to do that we will use the cases presented in Figure $6 b$ for different release heights. The recommended model results compared to Pepper's second moments model are shown in Figure 7. The curves in Figure 7 only show the distance range $1-100 \mathrm{~km}$ since Pepper's curve approaches small values outside that range. Pepper's results are much lower overall than the recommended Gaussian model. The only distance range at which these two models yield comparable concentrations is $\mathbf{8 - 1 5} \mathrm{km}$ downwind. It is not known with certainty why the models differ but we speculate the major difference is a result of the downdraft in our recommended model that brings material to the surface much faster than random mixing and the larger initial cloud size assumed in Pepper's model.

The recommended model is relatively easy to understand because of the simple Gaussian form of the model. The wind speed affects the time-integrated concentration $\Psi / Q$ inversely, and the release height and dispersion coefficients appear in exponential form. 


\section{Conclusions}

Recent research development and evolution of tornadic thunderstorms has lead to better understanding of the position of the tomado vortex and associated updraft and downdraft regions within the parent thunderstorm. Dispersion models previously used at SRS for estimating dispersion following a tornado strike (Pepper 1981; Haynes and Taylor 1983) do not adequately address the effects of these thunderstorm downdrafts. A revised model, which employs a simple Gaussian dispersion algorithm and provisions for a single persistent downdraft, has been developed for use at SRS.

The recommended model provides a means to estimate the maximum time-integrated concentration as a function of downwind distance for an F2 or F3 tornado strike. The results show the expected variation of time-integrated concentration with distance. The recommended model was expressly composed with conservative, yet reasonable assumptions regarding the major factors influencing dispersion after a tornado strike. Results are provided for ranges of wind speed, downdrafts, and initial release heights of the mesocyclone.

Time-integrated concentration estimates generated by the recommended model are much less than the results from the Haynes-Taylor model for the first few kilometers, but greater than the Haynes-Taylor estimates after 10 kilometers. The reason for this behavior is that the recommended model takes into account a strong, persistent downdraft whereas the Haynes-Taylor model does not. The HaynesTaylor model does account for rainout, but rainout cannot be guaranteed to occur in the brief aftermath of an $F 2$ or F3 tomado. The recommended model could be improved by providing for rainout and deposition if this should be desired in the future.
The recommended model gives X/Q values that are several orders of magnitude greater than the results from Pepper's model over most of the downwind range because of a single persistent downdraft in the recommended model and because Pepper assumed a larger initial cloud size. Pepper's results decrease more rapidly than the recommended model's results, probably because Pepper considered the scavenging process whereas the recommended model did not. Pepper does not provide enough information to compute $\Psi / Q$ for his model results.

The scenario considered here does not include an extended release after an F2 or F3 tornado strike. A tornado with winds in excess of $69 \mathrm{~m} / \mathrm{s}$ would likely result in a sudden release of materials into the tomado vortex. A less likely possibility is bleeding or slow discharge of the radionuclides after the tornado vortex moves over the damaged facility. This would require a more conventional approach because the dispersion would be primarily horizontal without the effect of significant updrafts or downdrafts. 
Anderson, C. E., 1985, "The Fall-Out Pattern for Debris from the Barneveld, WI Tornado: An F-5 Storm", Preprints, 14th Conf. on Severe Local Storms (Indianapolis, Indiana, Oct. 29-Nov. 1, 1985), pp. 289-92.

Bluestein, H. B., and J. H. Golden, 1993, "A Review of Tornado Observations, in The Tornado: Its Structure, Dynamics, Prediction, and Hazards", by C. Church, D. Burgess, C. Doswell, and R. Davies-Jones, Geophysical Monograph 79, American Geophysical Union, pp. 319-352.

Browning, K. A., 1964, "Airflow and Precipitation Trajectories Within Severe Local Storms Which Travel to the Right of the Winds", J. Atmos. Sci., 21, pp. 63439.

Coats, D. W., and R. C. Murray, 1985, Natural Phenomena Hazards Modeling Project: Extreme Wind/Tornado Hazard Models for Department of Energy Sites, UCRL-53526, Rev. 1, Lawrence Livermore National Laboratory, Univ. of California, Livermore, CA.

Davies-Jones, Robert P., 1986, Tornado Dynamics, Chapter 10 of Thunderstorm Morphology and Dynamics, University of Oklahoma Press, Norman, OK, E. Kessler (ed), pp. 197-236.

Davies-Jones, Robert P., and E. Kessler, 1974, Weather and Climate Modification, W. N. Hess (ed), John Wiley and Sons, Inc., pp. 552-595.

Egan, B. A., and J. R. Mahoney, 1972, "Numerical Modeling of Advection and Diffusion of Urban Area Source Pollutants", J. Appl. Meteorol., 11, pp. 312-322.

Fujita, T. T., and A. D. Pearson, 1973, "Results of FPP Classification of 1971 and 1972 Tomadoes", Preprints, Eighth Conference on Severe Local Storms, Denver, Colorado, American Meteorological Society, Boston, MA, pp. 142-45.

Fujita, T. T., 1981, "Tornadoes and Downbursts in the Context of Generalized Planetary Scales", J. Atmos. Sci., 38, pp. 1511-32.

Garrett, A. J., and C. E. Murphy, Jr., 1981, A Puff-Plume Atmospheric Deposition Model for Use at SRP in Emergency Response Situations, DP-1595, E. I. du Pont de Nemours \& Co., Savannah River Laboratory, Aiken, SC.

Golden, J. H., 1976, "An Assessment of Wind Speeds in Tornadoes", Proceedings, Symposium on Tornadoes: Assessment of Knowledge and Implications for Man, Lubbock, Texas, Texas Tech University, Lubbock, Texas, pp. 5-42.
Haynes, H. R., and D. H. Taylor, 1983, Estimating Doses from Tornado Winds, DPST-82-982, E. I. du Pont de Nemours \& Co., Aiken, SC.

Kao, S. K., 1976, "A Model for Turbulent Diffusion Over Terrain", J. Atmos. Sci., 33, pp. 157-158.

Kessler, E., 1994, Personal communication on the question of radionuclide dispersion by a tomado.

Kessler, E. (editor), 1992, Thunderstorm Morphology and Dynamics, University of Oklahoma Press, Norman, OK.

Lemon, L. R., and C. A. Doswell, 1979, "Severe Thunderstorm Evolution and Mesocyclone Structure as Related to Tornadogenisis", Mon. Weather Review, 107, pp. 1184-97.

Morton, B. R., 1966, Geophysical Vortices, Progress in Aeronautical Sciences, 7, Pergamon Press, New York, pp. 145-93.

Technical Memorandum 90, "Design Basis Tornado Characteristics", National Severe Storms Laboratory, Norman, OK.

Pepper, D. W., 1975, Dispersion of Small Particles in a Tornado, DP-1387, E. I. du Pont de Nemours \& Co., Savannah River Laboratory, Aiken, SC.

Pepper, D. W., 1981, Dispersion of Radioactive Pollutant in a Tornadic Storm, DP-1556, E. I. du Pont de Nemours \& Co., Savannah River Laboratory, Aiken, SC.

Peterson, R. E., 1993, "Far-Field Tomado Debris Patterns", Preprints, 17th Conf. on Severe Local Storms (St. Louis, Missouri, Oct. 4-8 1993), pp. 219-22.

Pasquill, F., and F. B. Smith, 1983, Atmospheric Diffusion, Third Edition, Halsted Press, John Wiley and Sons, New York.

U. S. Department of Energy, 1994, Natural Phenomenon Hazards Design and Evaluation Criteria for DOE Facilities, DOE-STD-1020-94, Washington, DC.

Wakimoto, R. M., 1983, "The West Bend, Wisconsin, Storm of 4 April 1981: A Problem in Operational Meteorology", J. Climate Appl. Meteorol, 22, pp. 181-89.

Wicker, L. J., 1990, A Numerical Simulation of a TornadoScale Vortex in a Three-Dimensional Cloud Model, Ph.D. thesis, Univ, of Ill., Urbana, Illinois.

Wicker, L. J., and R. B. Wilhelmson, 1993, "Numerical Simulation of Tornadogenesis Within a Supercell Thunderstorm, in The Tornado: Its Structure, Dynamics, Prediction, and Hazards", by C. Church, D. Burgess, C. Doswell, and R. Davies-Jones, Geophysical Monograph 79, American Geophysical Union, pp 7588. 
Wolford, L. V., 1960, Tornado Occurrences in the United

States, Technical Paper No. 20,, rev. ed., U. S.

Weather Bureau, Washington, D. C. 


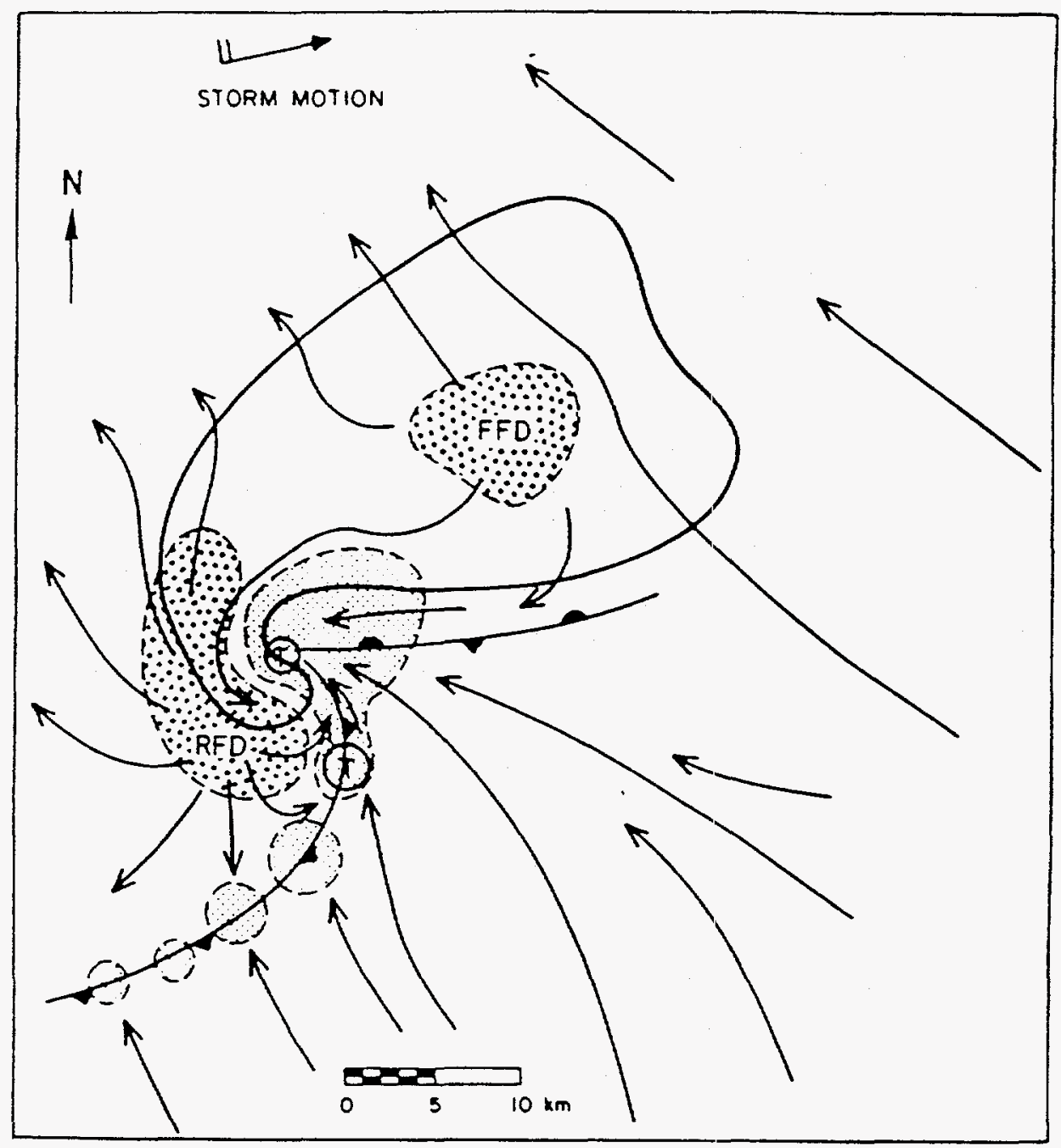

Figure 1. Planimetric view of a tornadic thunderstorm at the surface. The thick line encompasses the radar echo. The thunderstorm wave-like "gust-front" structure is shown with a solid line and frontal symbols. Surface positions of the updraft are finely stippled; the forward-flank downdraft (FFD) and the rear-flank downdraft are coarsely stippled along with associated streamlines. Likely tornado locations are shown by encircled Ts. The major cyclonic tornado is most probable at the wave apex, while a minor cyclonic tornado may occur at the bulge in the cold front (southern $\mathrm{T}$ ), which also marks the favored location for new mesocycione. Anticyclonic tornadoes, in any, are found even farther south along the cold front (from Davies-Jones [1986] who adapted the figure from Lemon and Doswell [1979]). 


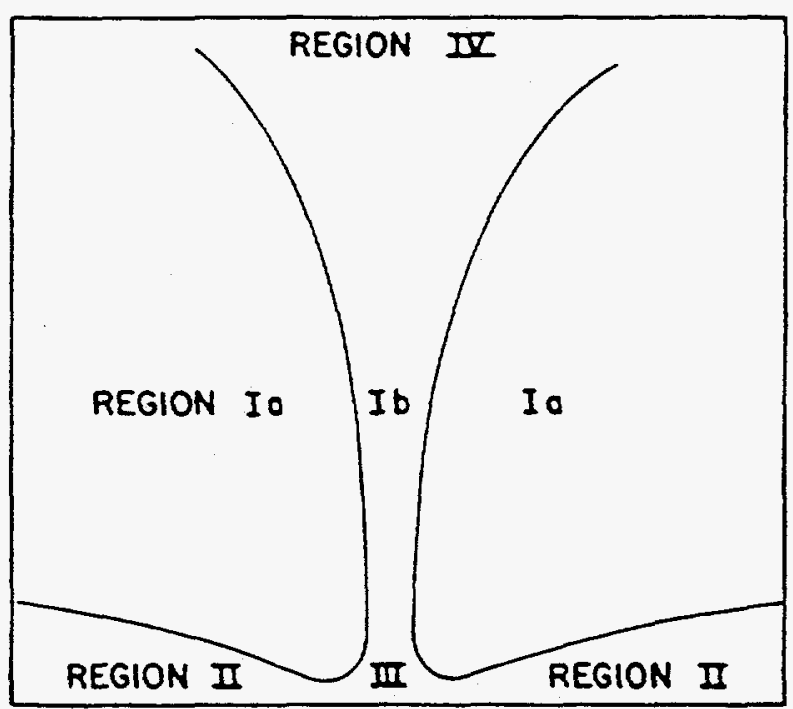

Figure 2. Different flow regions for a tornado (Davies-Jones 1986) 


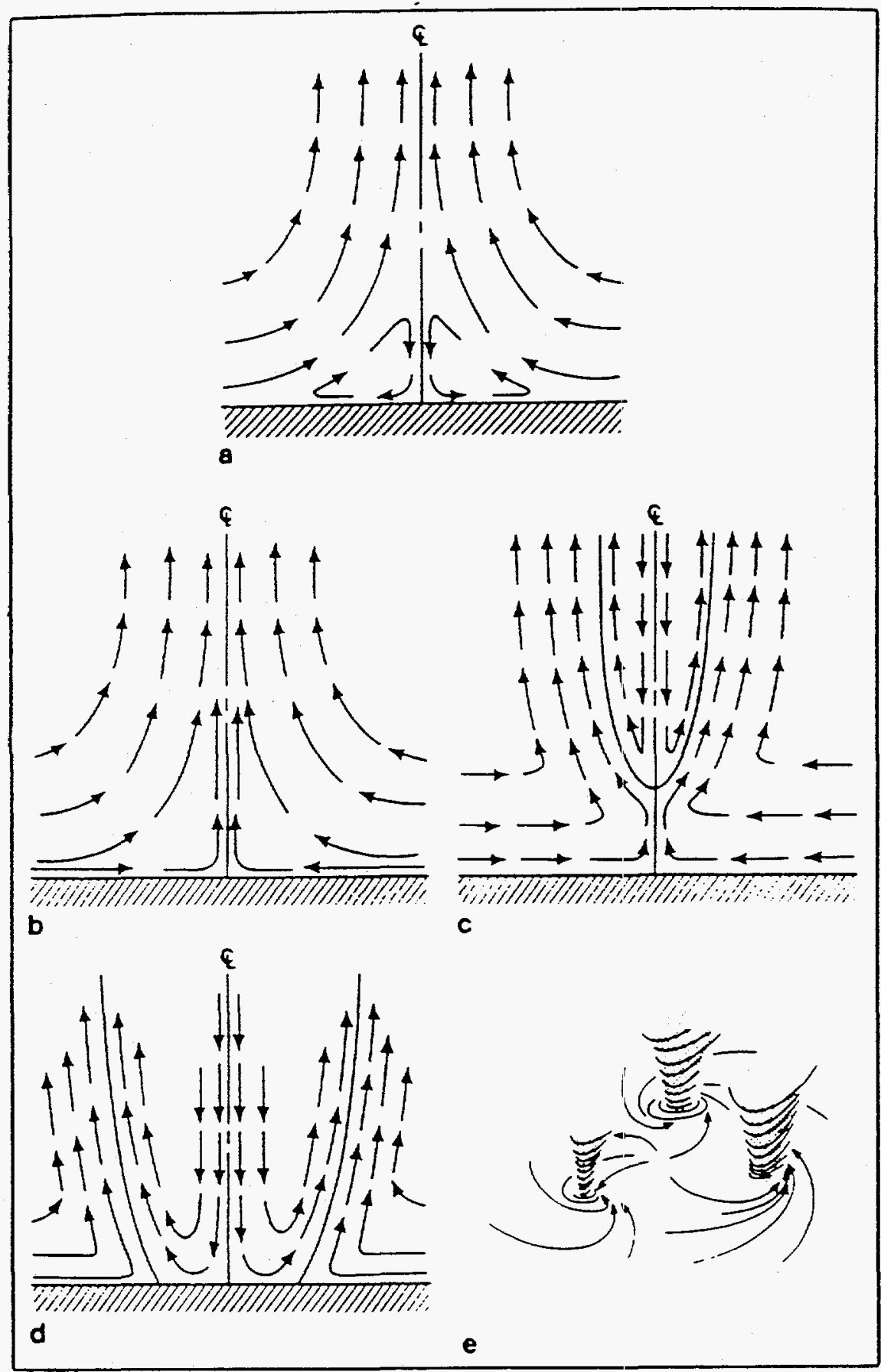

Figure 3. Effect of increasing swirl ratio on vortex flow. (a) Weak swirl-flow in boundary layer separates and passes around corner region; (b) one-cell vortex; (c) vortex breakdown; (d) two-cell vortex with downdraft impinging on the ground (core radius increases rapidly with increasing swirl ratio); (e) multiple vortices. The connected CL indicates the centerline (from Davies-Jones, 1986) 


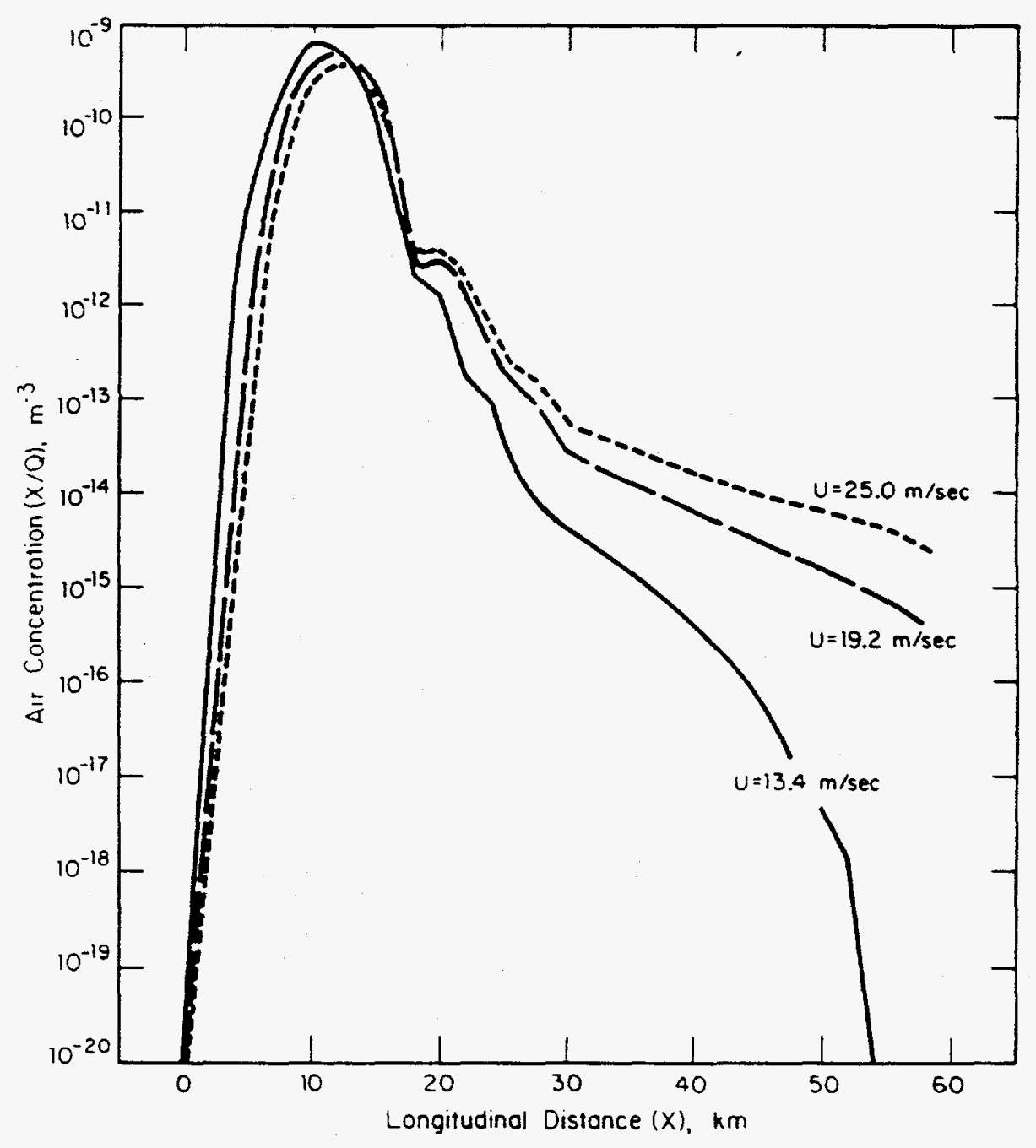

Figure 4. Maximum ground-level centerline air concentration $\left(\mathrm{m}^{-3}\right)$ vs. downwind distance $(\mathrm{km})$ from initialization point in storm from Pepper's second moments model (Pepper 1981) 


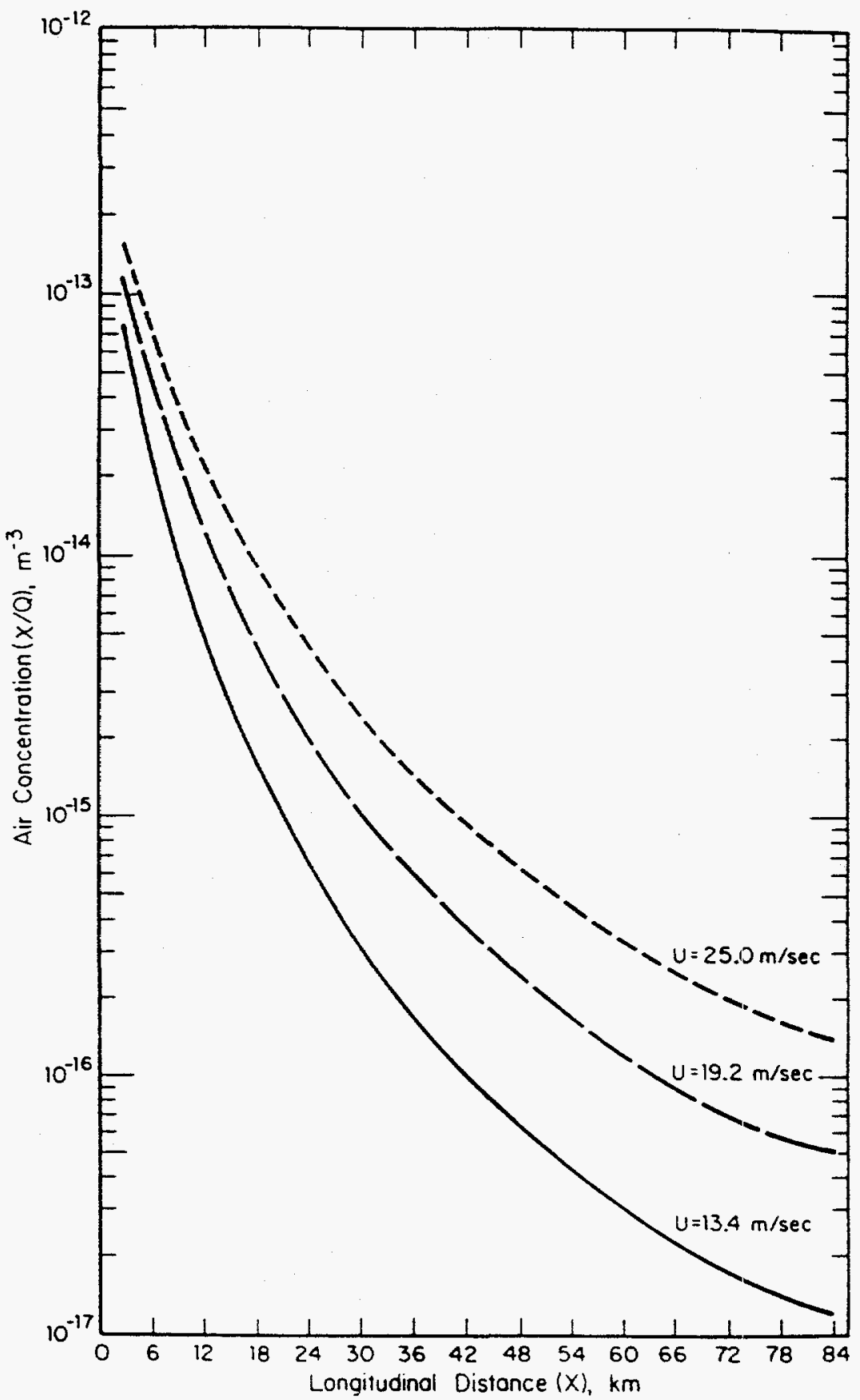

Figure 5. Maximum ground-level centerline air concentration $\left(\mathrm{m}^{-3}\right)$ vs. downwind distance $(\mathrm{km})$ from Pepper's Gaussian model (Pepper 1981) 

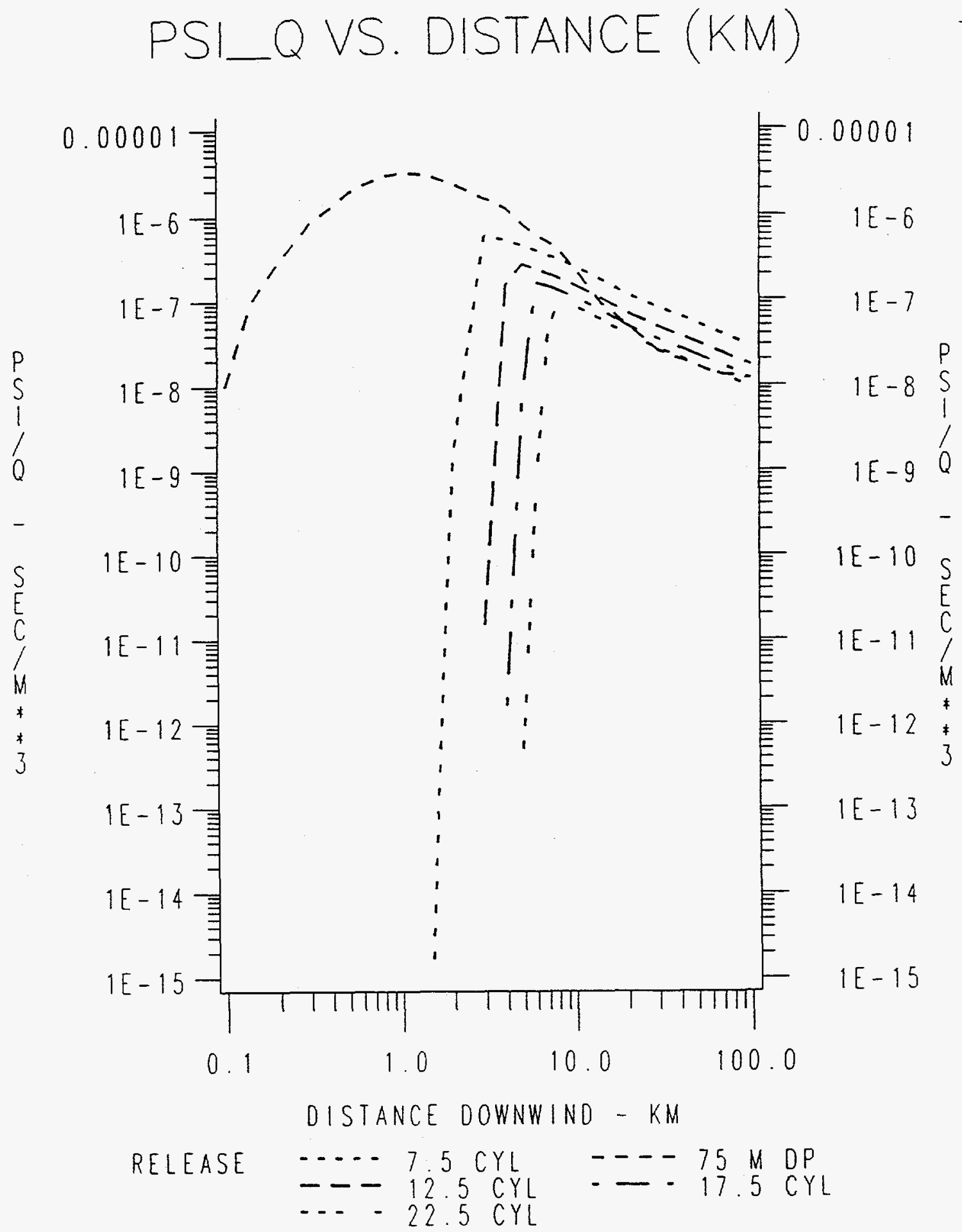

Figure 6a. Maximum time-integrated ground-level centerline air concentration $\left(\mathrm{sec} \mathrm{m}^{-3}\right)$ vs. downwind distance (km) for different mean translation speeds $7.5-22.5 \mathrm{~m} / \mathrm{sec}$. The downdraft speed is $10 \mathrm{~m} / \mathrm{sec}$ and the height of the cylindrical mesocyclone is $3500 \mathrm{~m}$. The Haynes and Taylor results are identified in the legend as' 75 M DP'. 

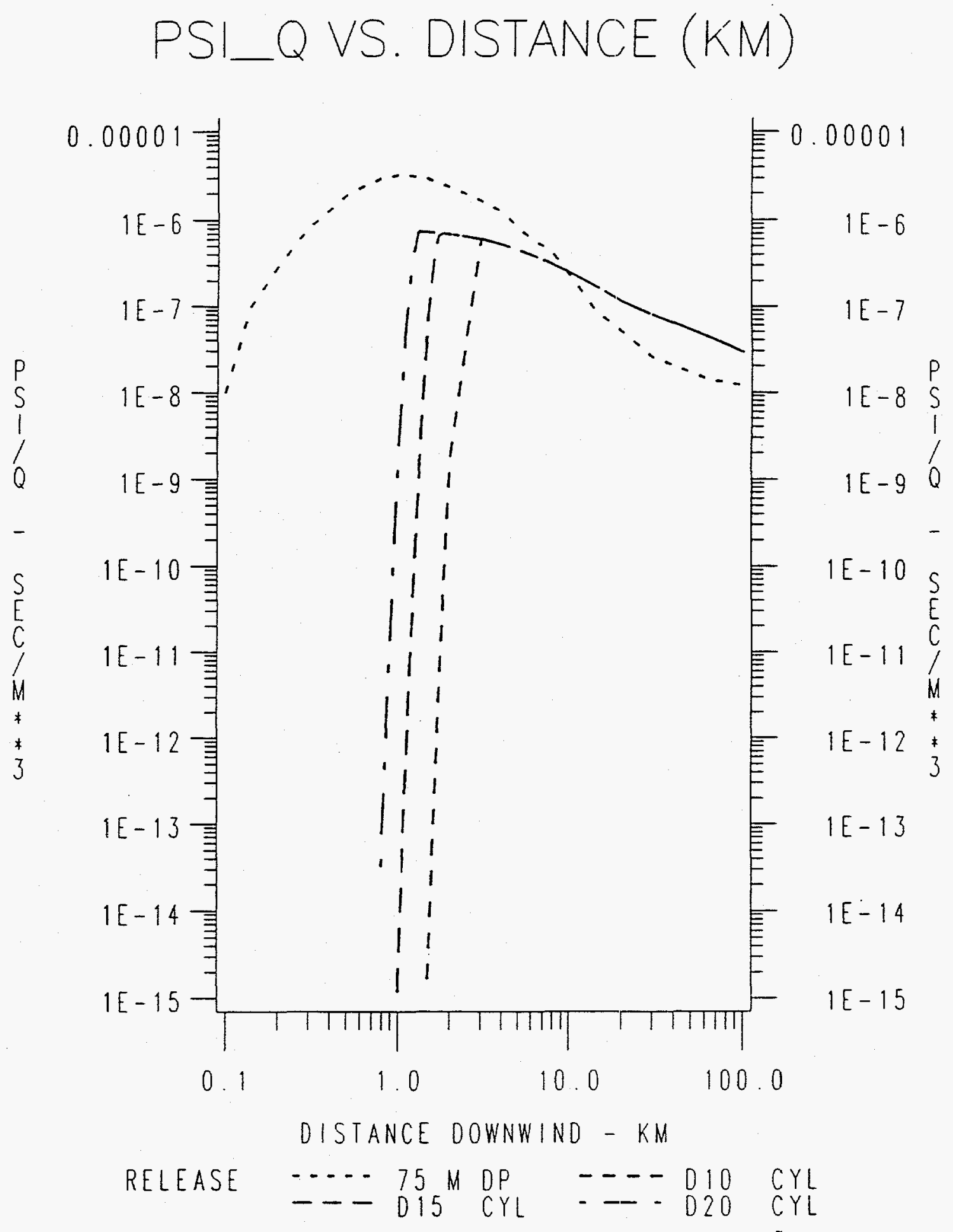

Figure 6b. As in Figure 6a except for different downdraft speeds $10-20 \mathrm{~m} / \mathrm{sec}$. The translation speed is $7.5 \mathrm{~m} / \mathrm{sec}$ and the height of the cylindrical mesocyclone is $3500 \mathrm{~m}$. 

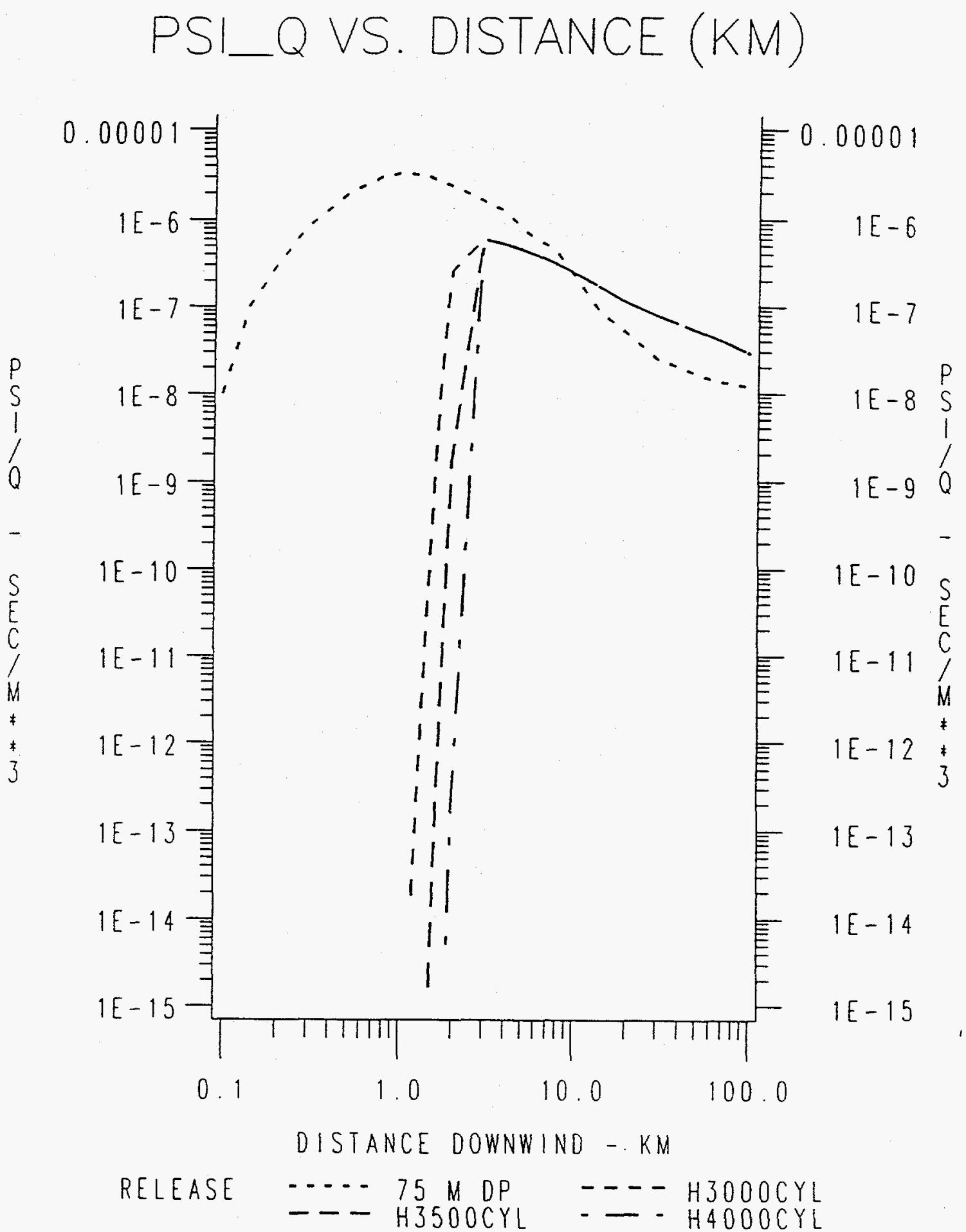

Figure 6c. As in Figure $6 b$ for different initial heights of the center of the mesocyclone cylindrical volume source. The translation speed is $7.5 \mathrm{~m} / \mathrm{sec}$ and the downdraft speed is $10 \mathrm{~m} / \mathrm{sec}$. 

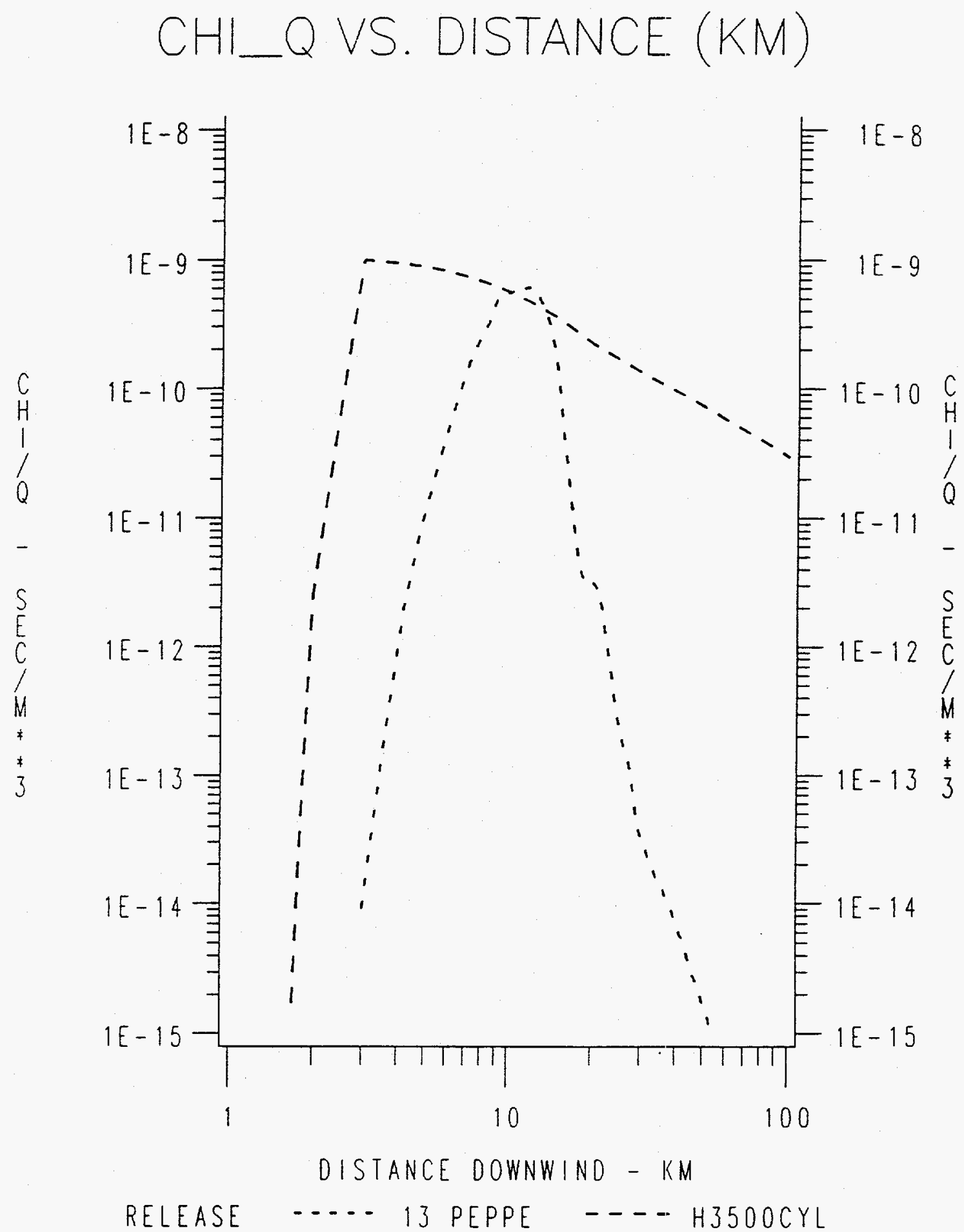

Figure 7. Maximum ground-level centerline air concentration $\left(\mathrm{m}^{-3}\right)$ vs. downwind distance $(\mathrm{km})$ from the recommended model with the translation speed $=7.5 \mathrm{~m} / \mathrm{sec}$, downdraft speed $=10 \mathrm{~m} / \mathrm{sec}$, and the release height $=3500 \mathrm{~m}(\mathrm{H} 3500 \mathrm{CYL})$; and from Pepper's (1981) second moments model with translation speed = 13.4 $\mathrm{m} / \mathrm{sec}(13 \mathrm{PEPPE})$ 


\section{Appendix A}

F-scale Damage Specifications (Fujita, 1981):

F0: $18-32 \mathrm{~m} / \mathrm{sec}$ (40-72 $\mathrm{mph}$ ). Light damage. Some damage to chimneys; branches broken off trees; shallowrooted trees pushed over; sign boards damaged.

F1: $33-49 \mathrm{~m} / \mathrm{sec}$ (73-112 mph). Moderate damage. Roof surfaces peeled off; mobile homes pushed off foundations or overturned; moving autos pushed off roads.
F2: $50-69 \mathrm{~m} / \mathrm{sec}$ (113-157 mph). Considerable damage. Roofs torn off frame houses; mobile homes demolished; boxcars pushed over; large trees snapped or uprooted; light object missiles generated.

F3: $70-92 \mathrm{~m} / \mathrm{sec}$ (158-206 mph). Severe damage. Roofs and some walls torn off well-constructed houses; trains overturned; most trees in a forrest uprooted; heavy cars lifted off the ground and thrown.

F4: $93-116 \mathrm{~m} / \mathrm{sec}$ (207-260 mph). Devastating damage. Well-constructed houses leveled; structures with weak foundations blown off some distance; cars thrown and large missiles generated. 


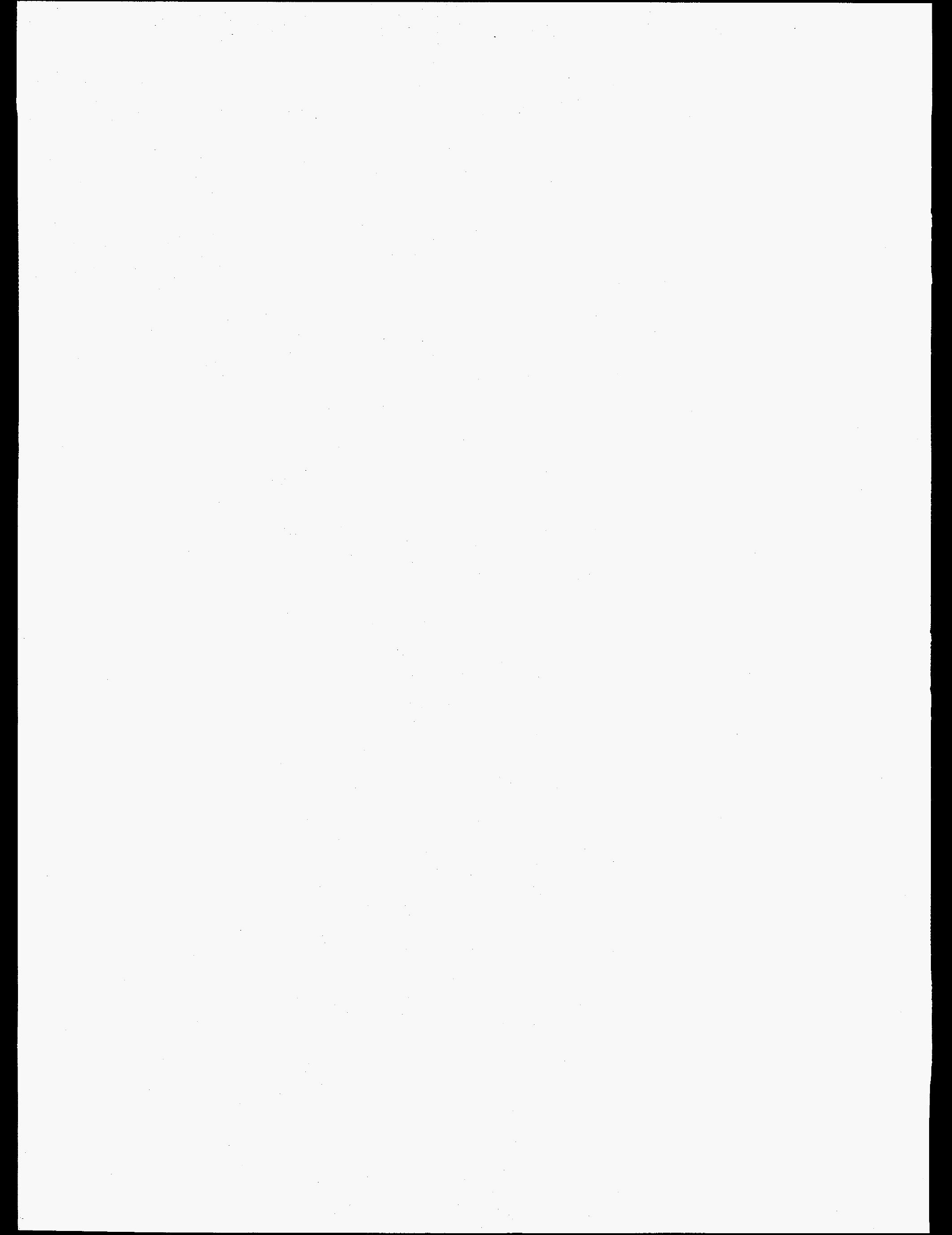

